\title{
PERANCANGAN SISTEM PEMILIHAN UMUM ELEKTRONIK BERBASIS WEB
}

\author{
Salsabila Delaisya Permana ${ }^{1}$, Rahmat Hidayat ${ }^{2}$, Yulindon ${ }^{3}$ \\ Teknologi Rekayasa Perangkat Lunak/Teknologi Informasi, Politeknik Negeri Padang ${ }^{1}$ \\ Email : salsabiladelaisyapermana@gmail.com ${ }^{1}$,rahmat@pnp.ac.id ${ }^{2}$, yulindon@pnp.ac.id ${ }^{3}$
}

\begin{abstract}
Abstrak
Pemilihan kepala daerah merupakan acara rutin yang diselenggarakan negara-negara di duniayang menganut sistem demokrasi. Pemilihan umum di Indonesia saat ini masih diselenggarakan secara konvensional dengan menggunakan surat suara yang terkadang menciptakan terjadinya beberapa masalah, antara lain jumlah surat suara yang tidak sesuai, menghabiskan lebih banyak waktu untuk menghitung surat suara, dan menghabiskan lebih banyak waktu untuk meninjau hasil suara, dan mungkin terdapat keteledoran pada tahapan prosedur. Kesalahan pendataan dan pengiriman surat, memilih pemilih. Melihat pesatnya perkembangan teknologi dewasa ini, sistem pemungutan suara elektronik dapat digunakan untuk pemilihan umum dimana teknologi informasi dan komunikasi sangat berpeluang besar untuk digunakan mulai dari tahap verifikasi, pemilihan dan penghitungan.Pada penelitian ini pemodelan desain bangunan sistem dilakukan dengan memakai model use case diagram dan activity diagram .
\end{abstract}

Kata kunci : Pemilu Elektronik ,Web, Perancangan Sistem ,Pemilihan Umum

\begin{abstract}
General elections are routine events held by countries in the world that adhere to democratic systems. Elections in Indonesia are currently held conventionally using ballots which creates several problems, including incorrect number of ballots, spending more time counting ballots, and spending more time reviewing ballot results, and there may be omissions. at this stage of the procedure. Choose data collection and mailing, choose voters. Seeing the rapid development of technology today, electronic voting systems can be used for general elections where information and communication technology is very likely to be used starting from the lever, selection and counting stages. In this study, the system building design modeling was carried out using the use case diagram and activity diagrams.
\end{abstract}

Keywords: e-voting,web,general election,design system

\section{Pendahuluan}

Naskah Indonesia termasuk salah satu negara yang mengedepankan demokrasi dan telah Menyelenggarakan empat kali pemilihan umum yang secara langsung dipilih oleh rakyat(Purwati, 2015) . Penyelengaaraan pemilu di Indonesia didasarkan atas azaz LUBERJURDIL (Langsung , Umum, Bebas, Rahasia, Jujur, Adil)."Langsung” maksudnya adalah dalam kondisi apapun pemilih tersebut harus langsung memilih atas nama pemilih, sedangkan "umum" artinya pemilihan umum dilaksanakan secara serentak di Indonesia ,sedangkan untuk pemilihan kepala daerah tingkat I dan daerah tingkat II dilaksanakan di daerah pada waktu yang bersamaan,Bebas berarti tidak mengintimidasi atau memaksa ke calon tertentu; rahasia berarti merahasiakan calon yang dipilih, dan tidak ada yang tahu siapa yang memilih siapa.jujur, tidak melakukan kecurangan, adil artinya seluruh pemilih memiliki hak dan kewajiban yang sama (Bakhri et al. 2013) (Sistem \& Online, 2013).

Saat ini Pemilu Indonesia dilaksanakan secara konvensional dengan menggunakan surat suara oleh warga negara yang berhak memilih yang kemudian datang ke TPS pada hari pencoblosan, dan warga negara yang berhak memilih tersebut lalu surat suara yang telah dicoblos dimasukkan ke dalam kotak suara yang telah disediakan,ketika proses pemungutan suara telah usai maka akan dilakukan penghitungan suara (Munir \& Utari, 2016). Prosedur pemilihan seperti itu terjadi terdapat banyak kekurangan, antara lain distribusi surat suara dan perlengkapan pemilu yang tidak memadai, kesalahan administrasi oleh pemilih dan calon, banyaknya surat suara yang tidak sah karena tanda yang salah pada surat suara, serta proses pengumpulan dan pemungutan suara yang lama. Demi mengatasi permasalahan tersebut salah satu jalan keluarnya yakni dengan melakukan pemilihan secara daring atau pemilihan elektronik(Wulansuci et al., 2018).

Suatu metode pemungutan suara dimana data direkam, disimpan dan diolah dalam bentuk informasi digital dinamakan pemungutan suara elektronik .Dengan kata lain, pemilihan elektronik mengacu pada sebuah proses pelaksanaan mulai dari pendaftaran pemilih, pelaksanaan pemilihan, 
penghitungan suara dan transmisi hasil pemungutan suara melalui sarana elektronik (sarana digital)(Ridwan et al., 2016). Menurut ahli pemungutan suara elektronik, metode Pemungutan suara ini(e-voting) dapat mempersingkat waktu yang dibutuhkan untuk penghitungan suara, memperotleh data yang tepat, menghindari terjadinya kekeliruan (error) serta mengurangi kemungkinan terjadinya kecurangan (cheating). Jika gugatan akan diajukan ke Mahkamah Konstitusi (MK), hasil akurat dari sistem pemungutan suara elektronik pasti akan membuat semua pihak mempertimbangkan kembali. Sekalipun pelaksanaan pemungutan suara elektronik menunjukkan adanya kecurangan, proses pemrosesannya akan lebih cepat, mudah, dan transparan( et al., 2015).Dalam merancang sistem pemungutan suara elektronik juga perlu memperhatikan kondisi geografis wilayah Indonesia, khususnya bagi aplikasi yang terpasang pada TPS yang ditempatkan dibeberapa daerah yang mengalami kendala pengaksesan jaringan komunikasi elektronik. Oleh karena itu, perlu adanya rancangan pemodel TPS yang dapat mengatasi permasalahan geografis tersebut (Sophan et al., 2012). untuk merealisasikan pemungutan suara elektronik maka diperlukan sebuah sistem informasi. Data yang diolah dari sistem informasi yang tepat akan menghasilkan sebuah informasi yang baik sehingga dapat membantu pihak pengambil keputusan memilih keputusan yang tepat (Adhi, 2014).

Pada beberapa tahun terakhir telah ada beberapa sistem pemilihan umum elektronik(evoting).Diantara sistem pemilihan umum elektronuk yang telah dibangun adalah sebagaimana yang telah dibuat oleh Edi Priyono pada tahun 2010 dengan judul E-Voting: Urgensi Transparansi Dan Akuntabilitas yang membahas mengenai perkembangan teknologi digital dan internet agar pemilu dapat dilaksanakan dengan transparan dan akuntabilitas yang terjamin(Priyono \& Dihan, 2010). Kemudian pada tahun 2019 Muhadi M.I.Gultom membuat sistem keamanan aplikasi e-voting dengan judul "Perancangan Sistem Keamanan Aplikasi EVoting Untuk Pemilihan Ketua Badan Eksekutif Mahasiswa Fakultas Teknik UISU Dengan Menggunakan Algoritma MD5 pada penelitian tersebut pengamanan pada sistem dilakukan dengan diterapkannya teknik kriptografi di dalam data pemilih(Data, 2019). Ditahun 2017 Slamet Risnanto membuah sebuah penelitian dengan judul Aplikasi Pemungutan Suara Elektronik/E-Voting Menggunakan Teknologi Short Message Service At Command yang menggunakan SMS dalam penyelenggaraan pemilihan umum elektronik,penggunaan SMS dilakukan karena hemat dalam penggunaan waktu serta keamanan,dan keakuratan data yang baik(Risnanto et al., 2017). Kemudian Dio Lavarino dan Dio Lavarino juga melakukan penelitian pada tahun 2016 dengan judul Rancang Bangun E - Voting Berbasis Website Di Universitas Negeri Surabaya yang membahas mengenai pembuatan rancangan sebuah sistem pemilihan umum elektronik di universitas dengan memakai PHP dan MySQL serta memakai teknik penghimpunan data dengan mewawancarai sekaligus voting(Dio Lavarino: Wiyli Yustanti, 2016). Pada tahun 2018 Clement Chan Zheng melakukan sebuah penelitian dengan judul Blockchain-Based Electronic Voting Protocol,penelitian ini membahas mengenai pemanfaatan teknologi blockchain sebagai fitur keamanan ,yang mana sistem tersebut mampu melindungi data diri masing-masing pemilih serta menjamin keaslian,mutu,dan anonimitas pemilih(Wei \& Wen, 2018). Pada tahun 2020 Faiq Zulfikar dan Ajib Susanto melakukan penelitian dengan judul Implementation Of Smart Contracts Ethereum Blockchain In Web-Bases Electronic Voting(E-Voting),penelitian ini membahas mengenai perekaman data pemilih yang menerapkan teknologi blockchain(Dzulfikar \& Susanto, 2020). Pada tahun 2015 A.Ahmad Yani,Andi Yudha Yunus ,danMuhammad Iqbal Latief melakukan penelitian dengan judul Participation Dynamics Of Voters Using Id Card In Local Elections: A Case Study Of The 2015 Local Election In South Sulawesi yang mengeksplorasi dinamika pemilih yang memakai KTP atau surat resmi lainnya dengan menyebutkan alasannya dalam menggunakan KTP(Yani et al., 2017) . Terlihat bahwa sistem pemilu tradisional yang telah berlangsung bertahun-tahun di Indonesia masih terdapat banyak kelemahan didalamnya, maka dari itu penulis berharap dapat merancang aplikasi pemungutan suara elektronik agar pemilu di Indonesia lebih efektif.

\section{Landasan Teori}

\subsection{Perancangan Sistem}

Perancangan sistem merupakan sebuah proses yang memuat langkah-langkah dalam pengolahan data serta langkah-langkah proses untuk mendukung pengoperasian sistem yang memiliki tujuan agar dapat memenuhi kebutuhan pengguna serta memberikan gambaran yang jelas dan lengkap untuk programmer dan pakar yang berkaitan. Sebuah sistem disusun oleh subsistem yang kemudian setiap subsistem tersebut juga disusun oleh subsistem atau komponen yang lebih kecil lagi. Kemudian interaksi antara subsistem merupakan unit integrasi atau integrasi. Integrasi sistem memungkinkan terciptanya kerjasama untuk menghasilkan informasi yang cepat, tepat dan akurat. 

September 2021, Perancangan Sistem Pemilihan Umum Elektronik Berbasis Web

\subsection{Pemilihan Umum (Pemilu)}

Pemilihan umum (Pemilu) merupakan sebuah proses yang dilakukan untuk memilih seseorang yang akan menduduki jabatan politik tertentu, baik jabatan dibidang eksekutif maupun legislatif. Didalam sebuah pemilu,seseorang yang memiliki hak suara untuk memilih disebut juga dengan konstituen,maka dalam kampanye peserta pemilu akan memberikan rencana yang akan ia lakukan nantinya jika menang didalam perhitungan suara pemilihan umum.

\subsection{Pemilu Elektronik}

Yang dimaksud dengan pemilihan elektronik adalah penggunaan hak suara dalam pemilihan yang menggunakan bantuan teknis (elektronik). Yang mana pemilu saat ini di Indonesia surat suara kertas masih digunakan untuk memilih pasangan calon yang akan dipilih. Namun, dengan pemungutan suara elektronik, surat suara tidak lagi menggunakan kertas tetapi dengan perangkat Elektronik yakni komputer yang sudah dipasangkan sistem didalamnya. Aplikasi pemungutan suara elektronik tidak hanya memberikan kemudahan dalam proses pemungutan suara,namun juga memberi kemudahan dalam proses penghitungan suara karena dilakukan secara daring, sehingga Anda bisa langsung mengetahui jumlah suara yang diterima dari hasil pemilu tanpa perlu melakukan penghitungan suara manual seperti proses manual.

\section{Metodologi Penelitian}

\subsection{Use Case Diagram}

Use Case Diagram merupakan sebuah abstraksi dari hubungan diantara perangkat dan aktor. Pada Use case diagram perincian fungsi yang disediakan oleh sistem diberikan dari sudut pandang pengguna.

Menurut Alistair Cockburn, use case diagram menjelaskan bagaimana sistem berperilaku dalam berbagai situasi dan bagaimana sistem menanggapi permintaan pengguna. Use case diartikan dari perspektif aktor yang relevan. Peserta adalah orang atau alat yang menggunakan sistem, dan bisa juga apa saja yang berinteraksi dengan sistem.

\subsection{Activity Diagram}

Diagram aktivitas adalah bentuk visual dari alur kerja yang berisi aktivitas dan tindakan, juga dapat berisi opsi, pengulangan, dan konkurensi. Dalam bahasa pemodelan terpadu, akan dibuat diagram aktivitas untuk menjelaskan alur aktivitas dan aktivitas komputer dalam organisasi

\section{Hasil dan Pembahasan}

Secara garis besar tahapan dalam pelaksanaan pemilihan umum dibagi menjadi tiga bagian yakni tahapan persiapan sebelum pemilihan umum dimulai dari pendataan calon yang akan dipilih,pendataan calon pemilih,pembagian TPS, dan distribusi peralatan pendukung lainnya,kemudian tahapan pada hari pemilihan umum,serta yang terakhir adalah tahapan setelah pemilihan umum yakni saat proses perhitungan suara.

a. Use Case Diagram

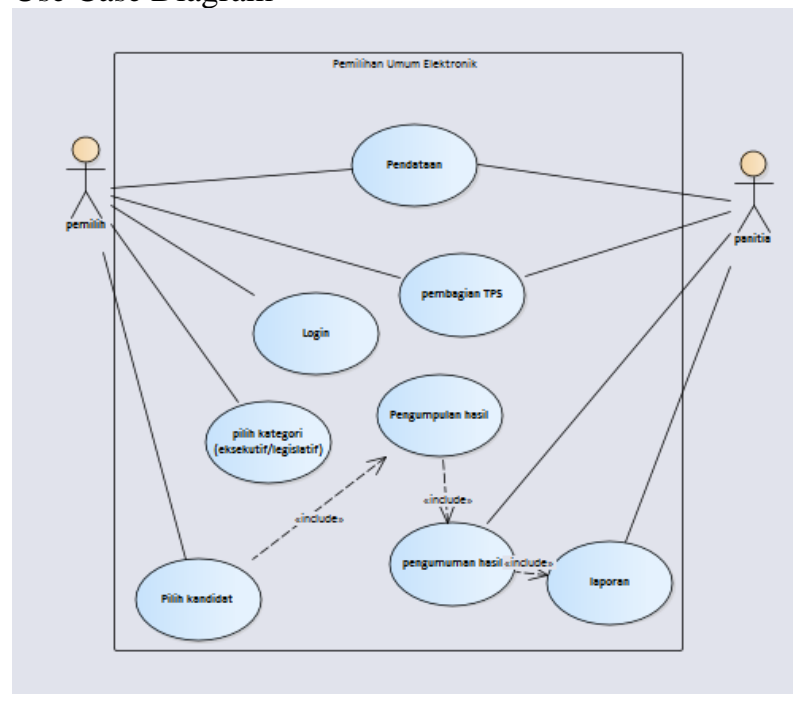

Gambar 1. Use Case Diagram

Berikut penjelasan dari Use Case Diagram pada gambar 1

Tahap Persiapan

\begin{tabular}{|l|l|}
\hline Nama Aktor & Pemilih \\
\hline Aksi & $\begin{array}{l}\text {-Pendataan data diri oleh panitia } \\
\text { - Mendapatkan info lokasi TPS }\end{array}$ \\
\hline
\end{tabular}

\section{Tabel 1}

\begin{tabular}{|l|l|}
\hline Nama Aktor & Panitia \\
\hline Aksi & $\begin{array}{l}\text { - Mendata identitas pemilih } \\
\text { - Memberikan info lokasi pemilih }\end{array}$ \\
\hline
\end{tabular}

Tabel 2

Tahap Pemilihan

\begin{tabular}{|l|l|}
\hline Nama Aktor 1 & Pemilih \\
\hline Aksi & - Melakukan login dengan \\
\hline
\end{tabular}


Jurnal Teknologi Informasi Dan Komunikasi, Issn : 2087-0868, Volume 12, Nomor 1, September 2021, Perancangan Sistem Pemilihan Umum Elektronik Berbasis Web

\begin{tabular}{|l|l|}
\hline menggunakan nama dan nik yang \\
sudah didaftarkan \\
- Memilih kategori yang akan di \\
voting (eksekutifllegislatif) \\
- Memilih calon / paslon pilihan
\end{tabular}

\section{Tabel 3}

Tahap Setelah Pemilihan

\begin{tabular}{|l|l|}
\hline Nama Aktor 1 & Panitia \\
\hline Aksi & - Merekap data yang sudah \\
& terkumpul \\
& - Membuat laporan hasil pemilu \\
& yang kemudian akan diumumkan \\
\hline
\end{tabular}

\section{Tabel 4}

b. Activity Diagram

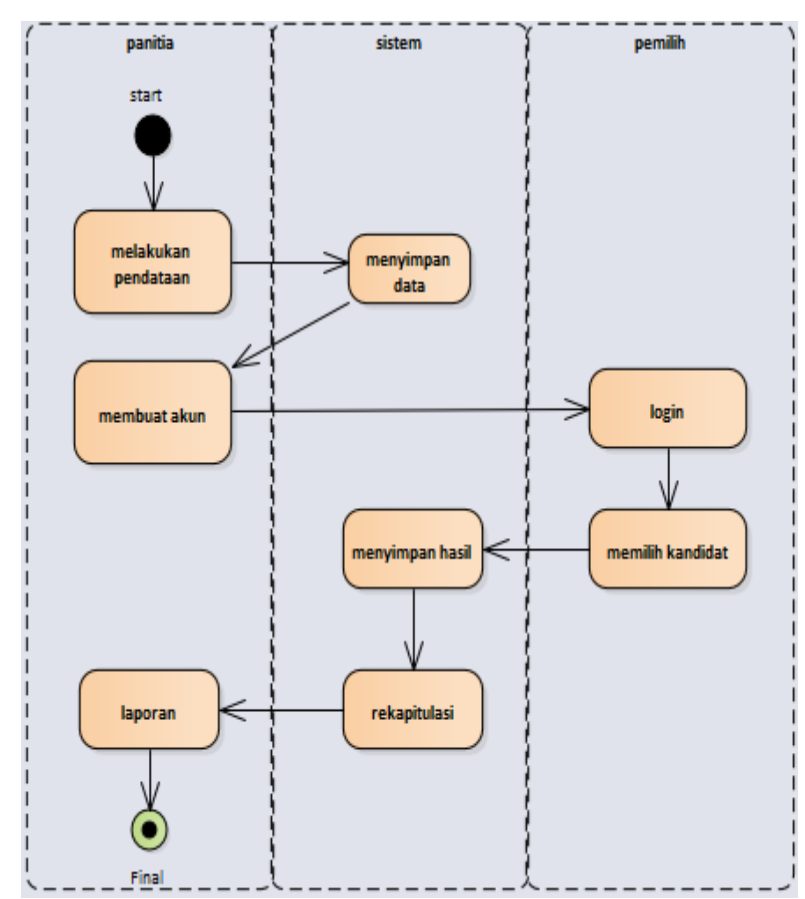

Gambar 2. Activity Diagram

c. Perancangan Interface dari Sistem Pemilu Elektronik

- Login Page

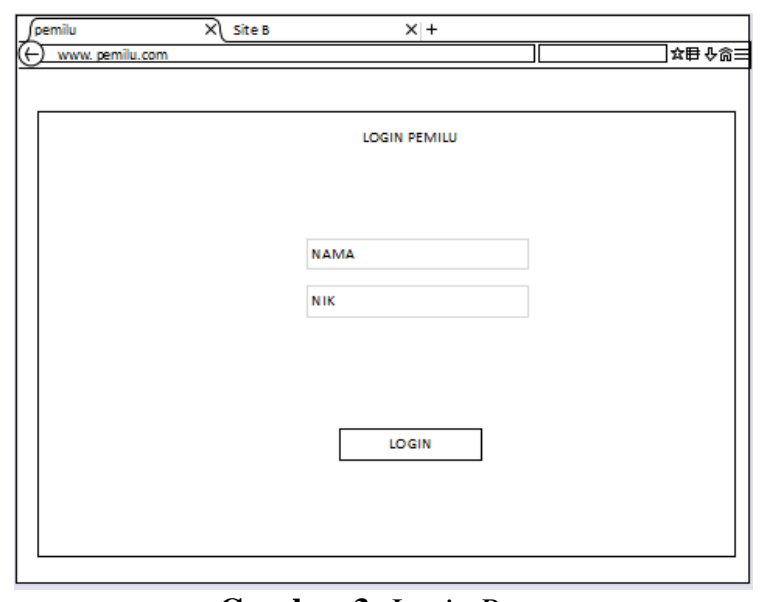

Gambar 3. Login Page
- Halaman Pemilihan Kategori

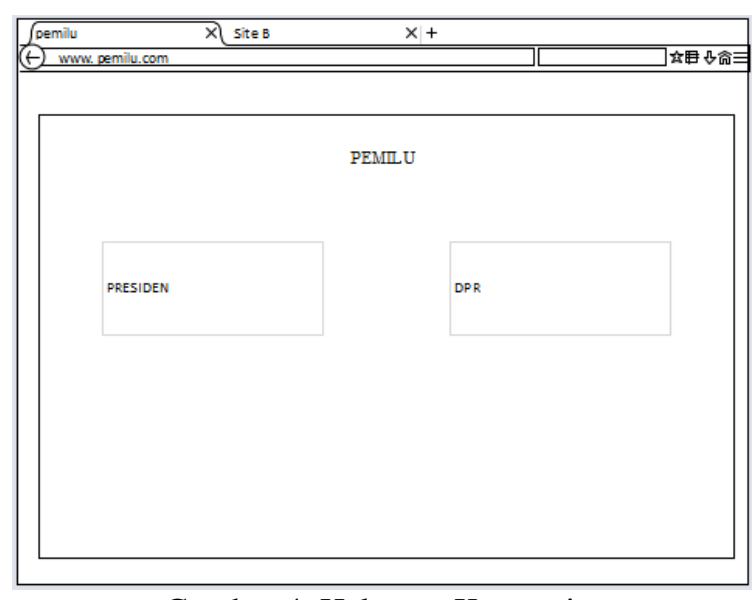

Gambar 4. Halaman Kategori

- Halaman Pemilihan Calon

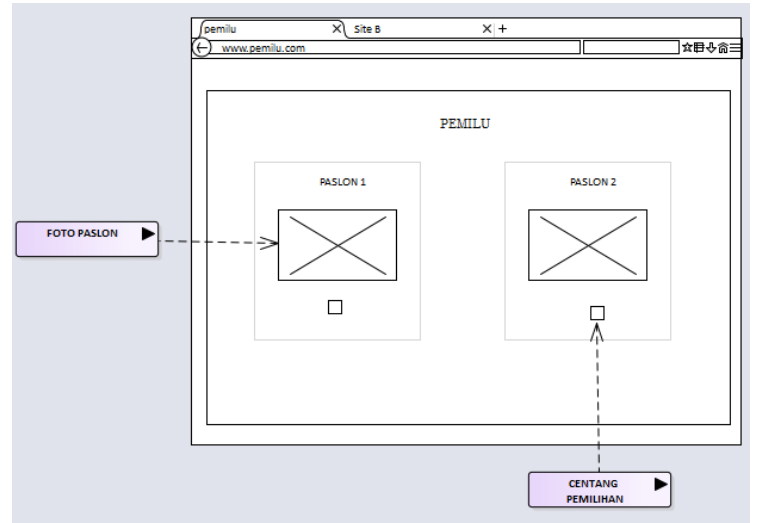


Jurnal Teknologi Informasi Dan Komunikasi, Issn : 2087-0868, Volume 12, Nomor 1, September 2021, Perancangan Sistem Pemilihan Umum Elektronik Berbasis Web

Gambar 5. Halaman Pemilihan Calon

\section{Daftar Pustaka}

Adhi, R. A. (2014). Rancang Bangun Sistem Informasi EKomputer, 11(2), 22.

Voting Berbasis SMS ( Developing E-Voting Information System SMS. III(November), 85-93.

Choer, Y. I., \& Kurniadi, D. (2015). Rancang Bangun Electronic Voting Pemilihan Kepala Daerah Kabupaten Garute Jurnal Algoritma. https://doi.org/10.33364/algoritma/v.142.146

Data, K. (2019). No Title. 6341(November), 70-77.

Dio Lavarino: Wiyli Yustanti. (2016). RANCANG

BANGUN E - VOTING BERBASIS WEBSITE DI UNIVERSITAS NEGERI SURABAYA. Jurnal Manajemen Informatika.

Dzulfikar, F., \& Susanto, A. (2020). Implementation of Smart Contracts Ethereum Blockchain in Web-Based Electronic Voting ( e-voting ). 18(1), 56-62.

Munir, A. Q., \& Utari, E. L. (2016). Pemanfaatan EKtp Untuk Proses Pemungutan Suara Pemilihan Umum Di Indonesia Menggunakan Sistem E-Vote.

Semnasteknomedia Online, 4(1), 2-4-1.

https://ojs.amikom.ac.id/index.php/semnasteknomedia/a rticle/view/1306

Priyono, E., \& Dihan, F. N. (2010). E-VOTING : URGENSI TRANSPARANSI DAN AKUNTABILITAS. 2010(32), 55-62.

Purwati, N. (2015). e-voting . Kata Kunci:pemilu,evoting, pilkada. 3(1).

Ridwan, M., Arifin, Z., \& Yulianto, Y. (2016).
Rancang Bangun E-Voting Dengan Menggunakan Keamanan Algoritma Rivest Shamir Adleman (RSA) Berbasis Web (Studi Kasus : Pemilihan Ketua Bem Fmipa). Informatika Mulawarman : Jurnal Ilmiah Ilmu https://doi.org/10.30872/jim.v11i2.210

Risnanto, S., Studi, P., Informatika, T., Teknik, F., \& Service, S. M. (2017). Aplikasi pemungutan suara rulektronik/ e-voting menggunakan teknologi short message service dan at command. 10(1). https://doi.org/10.15408/jti.v10i1.6811

Sistem, M., \& Online, P. (2013). UNNES Journal of Mathematics. 2(2).

Sophan, M. K., Rohman, T., Studi, P., Informatika, T., Teknik, F., Madura, U. T., \& Daerah, P. K. (2012). DESIGN MODEL TPS DALAM SISTEM. 2012(semnasIF), 160-167.

Wei, C. C. Z., \& Wen, C. C. (2018). Blockchain-based electronic voting protocol. International Journal on Informatics Visualization, 2(4-2), 336-341. https://doi.org/10.30630/joiv.2.4-2.174

Wulansuci, R., Rakhman, A., \& Salamah, I. (2018). Perancangan Alat E-Voting Untuk Pemilihan Umum. 65-69.

Yani, A. A., Yunus, A. Y., \& Latief, M. I. (2017). Participation Dynamics of Voters Using ID Card in Local Elections: A Case Study of the 2015 Local Election in South Sulawesi. Jurnal Ilmu Sosial Dan Ilmu Politik, 21(1), 41. https://doi.org/10.22146/jsp.28700 